\title{
Type 2 Diabetes Wellness Program in a Faith-Based Organization
}

\author{
Frenzy Papas Kiamco \\ Health Science, Walden University, Minneapolis, USA \\ Email: mondejar1@peoplepc.com
}

How to cite this paper: Kiamco, F.P. (2016) Type 2 Diabetes Wellness Program in a FaithBased Organization. Journal of Diabetes $\mathrm{Me}$ llitus, 6, 291-300.

http://dx.doi.org/10.4236/jdm.2016.64030

Received: October 18, 2016

Accepted: November 19, 2016

Published: November 22, 2016

Copyright (@) 2016 by author and Scientific Research Publishing Inc. This work is licensed under the Creative Commons Attribution International License (CC BY 4.0).

http://creativecommons.org/licenses/by/4.0/

(c) (i) Open Access

\begin{abstract}
In this practicum, the program objective is to improve the health of Joseph's Storehouse food bank recipients' community in the Blessing Center (New Hope Free Clinic and Joseph's food bank), Redlands, California. The approach is to implement primary prevention and secondary prevention activity to increase knowledge and skills of the clients and their families of how to prevent and control type 2 diabetes through a wellness program in the clinic. The practicum began January 2015 and ended April 2015. 53 food bank recipients (non-diabetic and diabetic) were recruited. A quasi-experimental study design, pre-test/posttest, was used for the study. The impact of the program targeted diverse audience, high risk ethnic groups, and improved knowledge, awareness, management, and positive behavioral change. The study implication for public health promotion specialists is to narrow venues targeting the most vulnerable populations to promote and reduce type 2 diabetes.
\end{abstract}

\section{Keywords}

Type 2 Diabetes, California, Faith-Based Organization, Diabetes Mellitus, Public Health, Wellness Program, Practicum, Primary Prevention, Secondary Prevention, Diabetes in California, Diabetes Disparity, Diabetes Education, Food Bank

\section{Introduction}

Studies have shown that in California, one of the chronic diseases such as diabetes is the seventh leading cause of death [1]. Diabetes mellitus is characterized by persistent hyperglycemia or increasing blood glucose levels (fasting plasma glucose concentration is $>7.0 \mathrm{mmol} / \mathrm{L}(>126 \mathrm{mg} / \mathrm{dL})$ or plasma glucose 2 hours after a standard glucose challenge is $>11.1 \mathrm{mmol} / \mathrm{L}(>200 \mathrm{mg} / \mathrm{dL})$ ) [1] [2]. There are many forms of diabetes: type 1, type 2, gestational, MODY and forms of MODY, and prediabetes; but the most common is type 2 diabetes [1] [2]. The development of type 2 diabetes links to various be- 
havioral factors (e.g., smoking, physical inactivity, etc.), predisposing factor, environmental factors (e.g., economics and culture) and so forth [1]-[10]. All forms of diabetes are associated with a number of complications such as cardiovascular, blindness, neurologic and kidney failure. Individuals with type 2 diabetes are also at a significantly higher risk for coronary heart disease, peripheral vascular disease, and stroke, and they have a greater likelihood of having hypertension, dyslipidemia and obesity [11].

Although improved glucose control can reduce the effects of these risks [3], today diabetes remains a burden on the population of California [1] [3]. In California, 1.9 million adults or 7 of every 100 have type 2 diabetes and the prevalence is unevenly distributed amongst race, gender, age, education, and income [1]. Statistical figures identified type 2 diabetes as

- the highest among the Hispanics with 1 in every 10 has this type of diabetes;

- predominant in African Americans and Asian/Pacific Islanders;

- higher among men by $13 \%$;

- increases with age (adults under age 45 type 2 diabetes is less than $2 \%, 10 \%$ for ages 45 - 64 years, and $17 \%$ for ages 65 years and older);

- two times higher in Californian adults without a high school diploma, and

- almost two times higher in those with family incomes below $200 \%$ of the federal poverty level [1].

The effects of the disease not only increase health disparities, but also burden the economy. In California approximately $\$ 98$ billion is spent on treating chronic conditions and about $29 \%$ of the spending is related to the cost of diabetes [3] [4].

To address the epidemic of type 2 diabetes in California, the California Department of Public Health (CDPH) has established multiple ongoing activities that promote primary prevention and secondary prevention that prevent and control type 2 diabetes or delay the onset of complications among Californians diagnosed with type 2 diabetes [1] [2] [12]. In this practicum, the aim of the program is to improve the health of Joseph's Storehouse food bank recipients' community in the Blessing Center (Hope Free Clinic and Joseph's food bank), Redlands, California. The approach is to implement primary prevention and secondary prevention activity to increase knowledge and skills of the clients and their families of how to prevent and control type 2 diabetes through a wellness program in the clinic.

\section{Methods}

The study began January 2015 and concluded in April 2015 and 53 food bank recipients (non-diabetic and diabetic) were recruited. A quasi-experimental study design, pretest/ posttest, was used for the study.

\subsection{Participants}

Joseph's Storehouse food bank clients. Low-income and homeless adults. 43 Hispanics (Mexican, Mexican American, and South American) and 6 of other races (African, African American, Asian, and Caucasian). 


\subsection{Preparation for the Classes}

Diabetes survey was administered to 59 clients of Joseph Storehouse food bank. Empirical literatures were researched and collected. Furthermore, a participant or participant's relative was recruited to translate Spanish when needed. Visuals were also created to supplement the lectures.

\subsection{Reaching Clients/Procedure}

To reach the clients three elements were utilized: communication materials, incentives, and referrals. Communication materials include: announcements, flyers, posters, preregistration, and referral [13] [14]. The routine to reach the clients comprised reminders via phone calls, announcements outside the Blessing Center, and informing each individual about the topic of the class in English and Spanish. In addition, clients were reminded of the incentives for participating in the class (they were exempt from waiting in line to get their food box). Another way to reach the clients was through referrals from the clinic nurse or announcement while the clients from the clinic were waiting for their lab work or doctor appointment. The class poster was advertised in the waiting room. All the participants who agreed to take part of the class provided verbal informed consent; and the first diabetic participants who took the first class verbally informed how many times they visited the emergency room for the month of January; completed knowledge pretest/posttest; and listened to lecture.

\subsection{Intervention/Education Session}

Eligible participants were given opportunity to take four primary prevention and management classes. The focal points of the lectures for diabetes, cholesterol and high blood pressure classes are the disease process, signs and symptoms, complications, prevention and managing the disease. The lesson plan includes:

- understanding insulin;

- Hemoglobin A1C or A1C check-up recommendation [15] [16];

- the difference between "good cholesterol" High Density Lipoprotein (HDL); and "bad cholesterol" Low Density Lipoprotein (LDL) [17] [18];

- how to identify normal blood pressure;

- different ways to increase fresh produce and the benefits of fresh produce;

- identifying various physical activities and discuss the benefits of physical activities [19].

Two sessions were scheduled every week for the duration of the practicum.

\subsection{Outcome Measurements}

Diabetes, cholesterol, blood pressure, and overall wellness knowledge questionnaires were employed in each lecture, pretests-posttests design [14] [20]. Each class had six questions except the overall wellness class which had 5 questions. Posttest scores average mean increase by at least $25 \%$ indicating health knowledge increase after taking the class. No more than 1 of these participants will visit the emergency room during the 
practicum indicating a positive outcome after two months follow-up. Demographic form was used to record number of participants. If at least 24 people participated for the duration of the practicum, it is indication of success in reaching the clients.

\subsection{Analysis}

SPSS was used to analyze the data. The statistical analysis concluded that the practicum was effective in promoting health knowledge significantly. Furthermore, the program goals were met emphasized from $0 \%$ knowledge in health literacy with regards to insulin, A1C, HDL, and LDL to increase literacy in insulin by $93 \%$, in A1C by $57 \%$, in HDL by $94 \%$, and LDL by $94 \%$.

\section{Results}

The impact of the program targeted diverse audience, high risk ethnic groups and improved knowledge and awareness, management, and behavioral change.

Fifty-three food bank recipients attended the type 2 diabetes wellness classes. Figure 1 displays that the class with the highest participation was the overall wellness class and the highest gender group that attended was the females. About $81 \%$ of the Hispanics group attended at least one of the classes $(\mathrm{N}=53)$ compared to other ethnic groups. Figure 2 shows that the highest age group ranges from 36 - 50 years old.

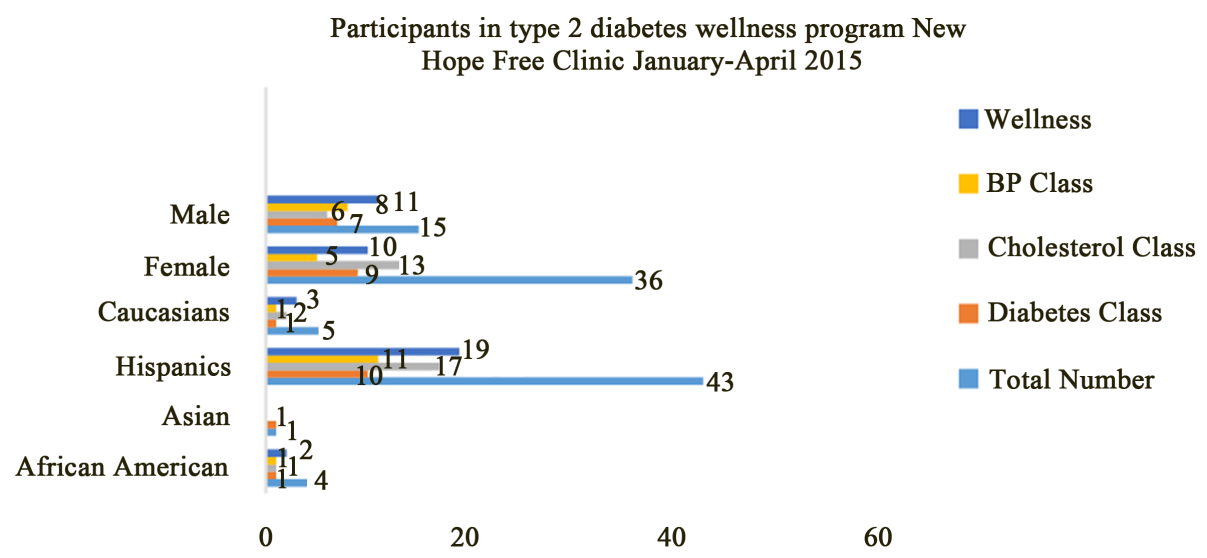

Figure 1. The graph shows total number ethnic groups and gender participated for each class.

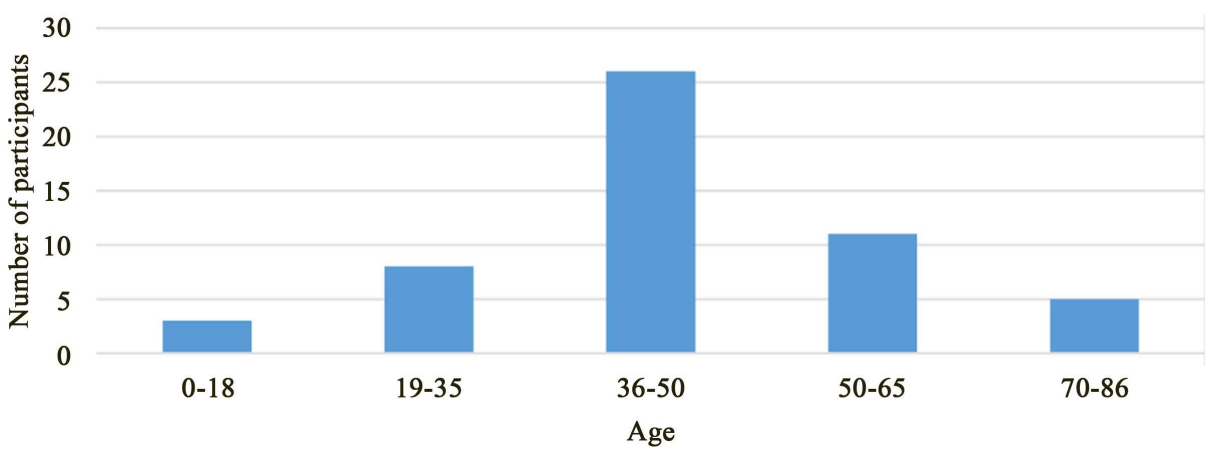

Figure 2. Age group for type 2 diabetes wellness program. 
Table 1 finding shows diabetes knowledge mean score increased by 1.96 (increased by $33 \%$ ), cholesterol knowledge mean score increased by 3.06 (increased by $52 \%$ ), blood pressure knowledge mean score increased by 1.75 (increased by $29 \%$ ), and overall wellness class knowledge mean score increased by 1.42 (increased by $30 \%$ ). A different analysis in Table 2 displays health literacy scores for non-diabetic and diabetic participants. For the A1C, insulin, HDL, and LDL, the participants scored 0 during pretest including participants who have history of diabetes. After taking the classes, for A1C, 8 of the 14 participants identified A1C check-up recommendation (increase by 57\%); for insulin, 13 of the 14 participants identified the meaning of insulin (increase by 93\%); for HDL, 15 of the 19 participants identified the meaning of HDL (increase by 94\%); and for LDL, 15 of the 19 participants identified the meaning of LDL (increase by $94 \%$ ).

Type 2 diabetic participants who took the diabetes class continued to control the disease after two months follow-up. Several participants verbally acknowledged the positive impact of the class including one participant who expressed his appreciation in writing. Visually, the positive shift in the mean score from diabetes pretests to diabetes posttests is noticeable in Figure 3 and Figure 4 where score mean increased from 3 in the pretest to 5 in the posttest with maximum score of 6 . However, does that mean difference statistically significant?

The statistical analysis affirms that the diabetes class made significant difference in knowledge level (did improve knowledge significantly) and shows the effectiveness of

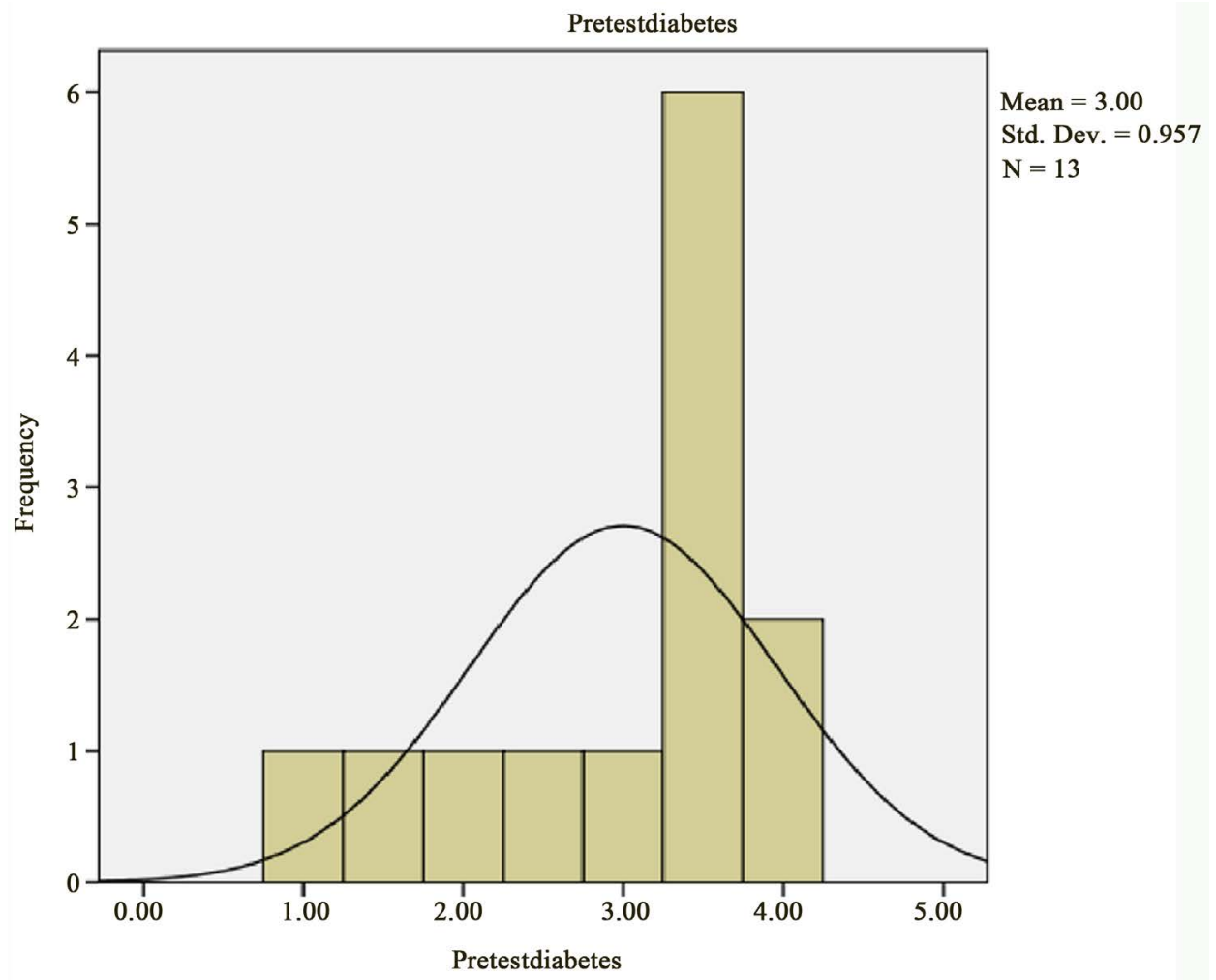

Figure 3. Pretests diabetes mean score. 


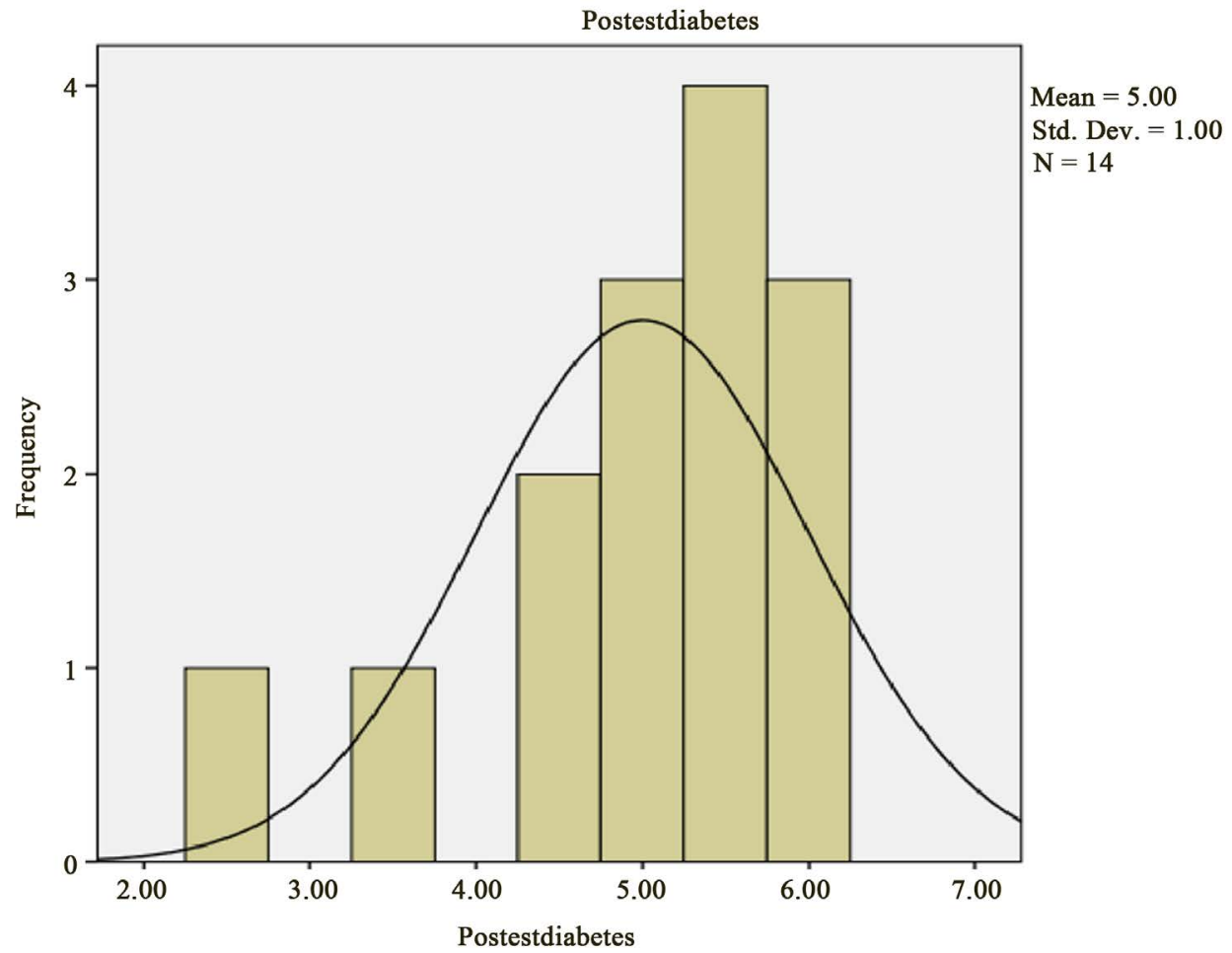

Figure 4. Posttests diabetes mean score.

Table 1. The bar shows score means for diabetes, cholesterol, blood pressure, and overall wellness class.

\begin{tabular}{cccc}
\hline Class & Pre-test Score Mean & Post-test Score Mean & Number of questions \\
\hline Diabetes & 3.00 & 5.00 & 6 \\
Cholesterol & 2.58 & 5.69 & 6 \\
Blood Pressure & 3.54 & 5.29 & 6 \\
Overall Wellness Class & 2.62 & 4.17 & 5 \\
\hline
\end{tabular}

Table 2. Number of correct answered by diabetic and non-diabetic for AIC check-up recommendation, meaning of insulin, and the difference between HDL and LDL pretests/posttest questions.

\begin{tabular}{ccccccc}
\hline $\begin{array}{c}\text { Health } \\
\text { literacy }\end{array}$ & $\begin{array}{c}\text { Pre-test } \\
\text { score }\end{array}$ & $\begin{array}{c}\text { Post-test } \\
\text { score }\end{array}$ & $\begin{array}{c}\text { Free of type 2 } \\
\text { participants }\end{array}$ & $\begin{array}{c}\text { History of type } \\
\text { 2 participants }\end{array}$ & $\begin{array}{c}\text { Number of } \\
\text { participant }\end{array}$ & $\begin{array}{c}\text { Number of participant } \\
\text { did not take the test }\end{array}$ \\
\hline ALC & 0 & 8 & yes & yes & 16 & 2 \\
Insulin & 0 & 13 & yes & yes & 16 & 2 \\
HDL & 0 & 15 & yes & yes & 19 & 3 \\
LDL & 0 & 15 & yes & yes & 19 & 3 \\
\hline
\end{tabular}

the class which was set as the alternative hypothesis versus the null hypothesis stating that the class did not make significant difference in knowledge (did not improve knowledge significantly). Table 3 shows that there is statistically significant evidence at alpha 
Table 3. Paired samples test for the mean difference between the diabetes pretests and posttests.

\begin{tabular}{|c|c|c|c|c|c|c|c|c|c|}
\hline & & \multicolumn{8}{|c|}{ Paired Differences } \\
\hline & & \multirow{2}{*}{ Mean } & \multirow{2}{*}{$\begin{array}{c}\text { Std. } \\
\text { Deviation }\end{array}$} & \multirow{2}{*}{$\begin{array}{l}\text { Std. } \\
\text { Error } \\
\text { Mean }\end{array}$} & $\begin{array}{r}95 \% \\
\text { Interval of }\end{array}$ & $\begin{array}{l}\text { dence } \\
\text { Difference }\end{array}$ & \multirow[t]{2}{*}{$\mathrm{t}$} & \multirow{2}{*}{ df } & \multirow{2}{*}{$\begin{array}{c}\text { Sig. } \\
\text { (2-tailed) }\end{array}$} \\
\hline & & & & & Lower & Upper & & & \\
\hline \multirow[b]{2}{*}{ Pair 1} & $\begin{array}{c}\text { Pretest } \\
\text { diabetes tests }\end{array}$ & -1.9615 & 1.45 & 0.40216 & -2.8377 & -1.0853 & -4.877 & 12 & 0.000 \\
\hline & $\begin{array}{c}\text { Posttest } \\
\text { diabetes tests }\end{array}$ & & & & & & & & \\
\hline
\end{tabular}

less than .005 of the significant improvement of in the mean score in the diabetes class. Likewise, the confidence interval of mean difference of scores in the diabetes class $[(\Sigma($ pretest score - posttest score $)) / \mathrm{n}]$ lies in its entirety in the negative portion of the real line (i.e., does not contain zero) leading to rejecting the null hypothesis of the ineffectiveness of the class.

\section{Discussion}

Clearly, faith-based organization (FBO) [21] [22] [23] that offers free services to the poor, low-income, and the underserved community is an asset to public health since the inceptions of clinics/hospitals by religious organizations. This type of venue allows public health to design and implement various health promotion activities to prevent chronic diseases from developing such as the type 2 diabetes.

Although a diminutive program and fewer resources were available, the type 2 diabetes wellness program contributed to the food bank recipients' community in significant ways. For one thing, the program was able to reach more than 24 participants and targeted ethnic group with the highest prevalence of type 2 diabetes in California $(\mathrm{N}=$ 53), (Hispanic $=43$ ). Secondly, food bank recipients who took the classes showed noticeable increase in knowledge after taking the class. Table 1 and Table 2 highlight clients' health knowledge and health literacy improvement after taking the classes (overall pretest and posttest scores mean increase ranges from $29 \%$ - 52\%). Furthermore, diabetic participants remained free from complications of type 2 diabetes after 2 months follow-up.

Primary prevention and secondary prevention are crucial to combat health disparity among people at risk of developing type 2 diabetes. There is now various studies postulate that type 2 diabetes can be prevented or delayed [11]. For example, a recent study by Psaltopoulou, Ilias, and Alevizaki (2010) [24] found that efforts such as eating healthier or physical exercise can reduce familial incidence. Another study by Johnson [14] suggested that education help eliminate racial disparities in diabetes. Well-known factors associated with health disparities are rooted in socio- economics, age, race or ethnicity, language spoken, physical disabilities, gender, and so on.

Community settings like the food banks accommodate persons who may exhibit one or more of these health disparity factors. For this reason, food banks would be an ideal 
site for primary and secondary prevention; however, mobilizing food bank agency may be challenging and overwhelming: 1) the premise of putting pressure on them to change food vendor selection (more on nutritional than less dense food) for distributions or turning their clients away to other food banks that distribute more "junk" foods or less restrictions on nutritional values; 2) most of the food bank recipients are always in a hurry; 3 ) less space or no space for engaging wellness classes for the food bank recipients; 4) fluctuation of food bank recipients status (homelessness, no transportation, relocated, and so forth.) may prevent them from attending series of workshops or classes.

A health wellness programs established in many worksites improving populationlevel health outcomes [25] can be applied in places like the food banks. Research shows that wellness programs offered to employees not only improve the health, but also have positive effects on the health care costs [26] [27]. Faith-based community centers may play an important role in reducing health care costs burden from type 2 diabetes by launching health programs in their community centers. In the practicum, although the results from the type 2 diabetes wellness class presented positive contribution to the food bank recipients, more studies about best practices for developing program [11] in food bank setting are encouraged to improve solutions combatting type 2 diabetes disparity in California. In addition, because many of food bank recipients participated in the wellness classes exhibited behavior changes such as getting physical exams for prevention measures, and expressed disappointments that the class ended, it suggests that food bank recipients are interested in health wellness programs.

\section{Conclusion}

Patients/clients accessed free health services (age range 16 - 89) at New Hope Clinic as well as free food from bank at Joseph's Storehouse where various efforts were made to improve their health. Health literacy and skills in prevention and control of Diabetes Mellitus outcome were measured by posttest scores and less frequency visits to the emergency room. Notable findings included increased knowledge and reduced doctor visits. Moreover, the objective of enrolling at least 24 participants has been met $(\mathrm{N}=$ 53). There were limitations. Sign and symptoms and fasting plasma glucose concentration $>126 \mathrm{mg} / \mathrm{dL}$ or plasma glucose 2 hours after a standard glucose challenge $>200$ $\mathrm{mg} / \mathrm{dL}$ were not in the study because audience and units of measurements vary from place to place. Also, the follow-up was diminutive because the practicum duration was four months and there was no control group. The study implication for public health promotion specialists may narrow venues targeting the most vulnerable populations to promote and reduce type 2 diabetes.

\section{Acknowledgements}

All the participants who agreed to take part in the class provided informed verbal consent during recruitment and at the beginning of the class. Neither medical records were used nor medical procedure done to participants. 


\section{References}

[1] Burden of Diabetes in California. California Department of Public Health. http://www.cdph.ca.gov/programs/cdcb/Documents/FINAL\%20Rpt\%20(1877)\%20DM\%20 burden\%202014_8-6-14.pdf

[2] Genetics and Diabetes. World Health Organization. http://www.who.int/genomics/about/Diabetis-fin.pdf

[3] Brown, P.M., Gonzalez, M. and Dhaul, R.S. (2015) Cost of Chronic Disease in California: Estimates at the County Level. Journal of Public Health Management \& Practice, 21, E10E19.

[4] American Diabetes Association (2013) Economic Costs of Diabetes in the U.S. in 2012. Diabetes Care, 36, 1033-1046. http://dx.doi.org/10.2337/dc12-2625

[5] Health Literacy. National Network of Libraries of Medicine. http://nnlm.gov/outreach/consumer/hlthlit.html

[6] Hill, J., Nielsen, M. and Fox, M.H. (2013) Understanding the Social Factors That Contribute to Diabetes: A Means to Informing Health Care and Social Policies for the Chronically Ill. The Permanente Journal, 17, 67-72. http://dx.doi.org/10.7812/TPP/12-099

[7] McAfee, T., Davis, K.D., Alexander, R.L., Pechacek, T.F. and Bunnell, R. (2013) Effect of the First Federally Funded US Antismoking National Media Campaign. The Lancet, 382, 2003-2011. http://dx.doi.org/10.1016/S0140-6736(13)61686-4

[8] (2008) Policy Changes to Improve the Value We Need from Health Care. Institute of Medicine (US). Evidenced-Based and the Changing Nature of Healthcare: 2007 IOM Annual Meeting Summary. National Academies Press, Washington DC. http://www.ncbi.nlm.nih.gov/books/NBK52830/

[9] Seligman, H.K., Laraia, B.A. and Kushel, M.B. (2010) Food Insecurity Is Associated with Chronic Disease among Low-Income NHANES Participants. Journal of Nutrition, 140, 304-310. http://dx.doi.org/10.3945/jn.109.112573

[10] Wannamethee, S.G., Shaper, A.G. and Perry, I.J. (2001) Smoking as a Modifiable Risk Factor for Type 2 Diabetes in Middle-Aged Men. Epidemiology/Health Services/Psychosocial Research. Diabetes Care, 24, 1590-1595. http://www.tcsg.org/tobacco/T2RiskMidAgeMen.pdf

[11] American Diabetes Association National Institute of Diabetes and Digestive and Kidney Diseases (2004) Prevention or Delay of Type 2. Diabetes Care, 27, S47. http://dx.doi.org/10.2337/diacare.27.2007.S47

[12] Burden of Cardiovascular Diseases in California. California Department of Public Health. http://www.cdph.ca.gov/programs/cvd/Documents/CHDSP-BurdenReport-LowRes.pdf

[13] Castillo, A., Giachello, A., Bates, R., et al. (2010) Community-Based Diabetes Education for Latinos. The Diabetes Educator, 36, 586-594. http://dx.doi.org/10.1177/0145721710371524

[14] Johnson, J., Levi, R., Iwanenko, W., Schiffert, J. and Sen, A. (2012) Are Podcasts Effective at Educating African-American Men about Diabetes? American Journal of Men's Health, 6, 365-367. http://dx.doi.org/10.1177/1557988312444717

[15] Healthy People 2020 Leading Health Indicators: Clinical Preventive Services. Healthy People. https://www.healthypeople.gov/sites/default/files/HP2020_LHI_Clin_Prev_Srv_0.pdf

[16] Gallivan, J., Greenberg, R. and Brown, C. (2008) The National Diabetes Education Program Evaluation Framework: How to Design an Evaluation of a Multifaceted Public Health Education Program. Preventing Chronic Disease, 5, A134. 
http://www.ncbi.nlm.nih.gov/pmc/articles/PMC2578767/

[17] Marais, A.D. (2004) Familial Hypercholesterolaemia. The Clinical Biochemist Reviews, 25, 49-68. http://www.ncbi.nlm.nih.gov/pmc/articles/PMC1853359/

[18] Upadhyay, D.U., Waddell, N.E., Young, S., et al. (2010) Prevalence, Awareness, Treatment, and Control of High LDL Cholesterol in New York City, 2004. Preventing Chronic Disease, 7, A61. http://www.ncbi.nlm.nih.gov/pmc/articles/PMC2879993/

[19] Thompson-Reid, P.E. (2009) Engaging and Mobilizing Community Members to Prevent Obesity among Adolescents. Preventing Chronic Disease, 6, A100.

http://www.ncbi.nlm.nih.gov/pmc/articles/PMC2722392

[20] Delucchi, M. (2014) Measuring Student Learning in Social Statistics: A Pretest-Posttest Study of Knowledge Gain. American Sociological Association, 42, 231-239. http://dx.doi.org/10.1177/0092055x14527909

[21] Barot, S. (2013) A Common Cause: Faith-Based Organizations and Promoting Access to Family Planning in the Developing World. Guttmacher Policy Review, 16, 18-23. https://www.guttmacher.org/sites/default/files/article_files/gpr160418.pdf

[22] DeHaven, J.M., Hunter, B.I., Wilder, L., Walton, W.J. and Berry, J. (2004) Health Programs in Faith-Based Organizations: Are They Effective? American Journal of Public Health, 94, 1030-1036. http://www.ncbi.nlm.nih.gov/pmc/articles/PMC1448385/ http://dx.doi.org/10.2105/AJPH.94.6.1030

[23] Kaplan, A.S., Calman, S.N., Golub, M., Ruddock, C. and Billings, J. (2006) The Role of Faith-Based Institutions in Addressing Health Disparities: A Case Study of an Initiative in the Southwest Bronx. Journal of Health Care for the Poor and Underserved, 17, 9-19. http://dx.doi.org/10.1353/hpu.2006.0088

[24] Psaltopoulou, T., Ilias, I. and Alevizaki, M. (2010) The Role of Diet and Lifestyle in Primary, Secondary, and Tertiary Diabetes Prevention: A Review of Meta-Analyses. Review of Diabetic Studies, 7, 26-35. http://dx.doi.org/10.1900/RDS.2010.7.26

[25] Fonarow, C.G., Calitz, C., Arena, R., et al. (2015) Workplace Wellness Recognition for Optimizing Workplace Health. Circulation, 131, e480-e497. http://dx.doi.org/10.1161/CIR.0000000000000206

[26] Baicker, K., Cutler, D. and Song, Z. (2010) Workplace Wellness Programs Can Generate Savings. Health Affairs, 29, 304-311. http://dx.doi.org/10.1377/hlthaff.2009.0626

[27] Mattke, S., Liu, H., Caloyeras, P.J., et al. (2013) Workplace Wellness Programs Study. RAND Health. http://www.rand.org 
Submit or recommend next manuscript to SCIRP and we will provide best service for you:

Accepting pre-submission inquiries through Email, Facebook, LinkedIn, Twitter, etc. A wide selection of journals (inclusive of 9 subjects, more than 200 journals)

Providing 24-hour high-quality service

User-friendly online submission system

Fair and swift peer-review system

Efficient typesetting and proofreading procedure

Display of the result of downloads and visits, as well as the number of cited articles

Maximum dissemination of your research work

Submit your manuscript at: http://papersubmission.scirp.org/

Or contact jdm@scirp.org 